See Article page 1.

\section{Commentary: Management of acute type A aortic dissection with patent false lumen: A rivalry between surgical data and philosophy}

Irbaz Hameed, MD, Arnar Geirsson, MD, and Roland Assi, MD, MMS

For patients with persistent false lumen and malperfusion following acute type A aortic dissection (TAAD), prognosis remains dismal despite heroic surgical measures. The Canadian Thoracic Aortic Collaborative reviews the management of this complication in their timely article. ${ }^{1}$ They discuss the pathophysiology of acute TAAD repair and distal anastomotic new entry tear following hemiarch repair based on contemporary open and endovascular surgical strategies for aortic arch management.

Distal anastomotic new entry tear is not uncommon following acute TAAD repair despite rigorous surgical technique and recent innovations. ${ }^{2}$ This predisposes the recovering aorta to persistent antegrade pulsatile false lumen pressurization that can hamper long-term downstream remodeling. Multiple approaches attempting to effectively seal distal anastomoses, preserve true lumen patency, and mitigate new entry tears have been espoused by different groups. ${ }^{3,4}$

The current spectrum of treatment algorithms ranges from anastomotic techniques of reinforcing suture lines using biological sealants and polytetrafluoroethylene felt, to strategies based on graft implantation and stenting. The latter mainly comprise total arch replacement, hybrid

\footnotetext{
From the Division of Cardiac Surgery, Department of Surgery, Yale School of Medicine, New Haven, Conn.

Disclosures: The authors reported no conflicts of interest.

The Journal policy requires editors and reviewers to disclose conflicts of interest and to decline handling or reviewing manuscripts for which they may have a conflict of interest. The editors and reviewers of this article have no conflicts of interest.

Received for publication June 6, 2021; revisions received June 6, 2021; accepted for publication June 18, 2021; available ahead of print June 23, 2021.

Address for reprints: Roland Assi, MD, MMS, Division of Cardiac Surgery, Department of Surgery, Yale School of Medicine, 330 Cedar St, New Haven, CT 06510 (E-mail: roland.assi@yale.edu).

JTCVS Techniques 2021;9:13-4

2666-2507

Copyright (C) 2021 The Authors. Published by Elsevier Inc. on behalf of The American Association for Thoracic Surgery. This is an open access article under the CC BY-NCND license (http://creativecommons.org/licenses/by-nc-nd/4.0/).

https://doi.org/10.1016/j.xjtc.2021.06.022
}

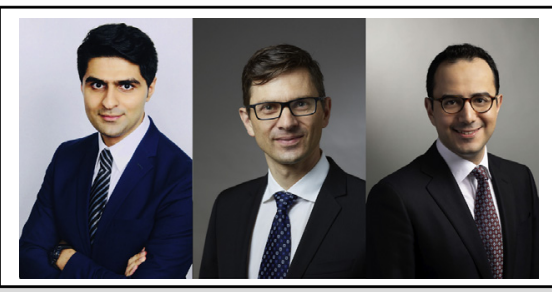

Irbaz Hameed, MD, Arnar Geirsson, MD, and Roland Assi, MD, MMS

\author{
CENTRAL MESSAGE \\ The treatment strategy for acute \\ type A aortic dissection must \\ consider all patient variables, \\ disease etiology, and distinct pa- \\ tient anatomy over personal \\ surgical philosophy.
}

approaches with conventional or frozen elephant trunk, zone 2 partial total arch replacement with subsequent thoracic endovascular aortic repair, and type II hybrid arch replacement. Newer techniques rely on the use of bare-metal stents across the aortic arch and/or descending aorta at the time of the index surgery to reinforce true lumen expansion. The evidence supporting the use of these novel techniques is limited to small studies.

Although all strategies seemingly offer sound options for managing persistent false lumen and malperfusion, it must be underscored that no single strategy is necessarily better than the others and each has specific technical nuances, advantages, and disadvantages. In fact, certain complex scenarios may demand more than 1 surgical and endovascular technique depending on the aortic pathology, patient anatomy, comorbidities, and surgeon/institutional experience. ${ }^{5,6}$ In addition to tailoring the correct strategy to each individual patient, aortic surgeons confronted with acute TAAD with malperfusion must carefully inspect downstream aorta for re-entry tears on preoperative angiograms and be meticulous when anastomosing around weak and damaged tissue. Further, careful consideration must be given to stent and graft sizing to prevent downstream re-entry tears as well as minimize risk of postoperative spinal cord injury. Beyond the operating room, rigorous hemodynamic monitoring and maintaining adequate cerebrospinal fluid pressure are critical to mitigate postoperative complications.

The absence of randomized data and long-term longitudinal studies render all treatment strategies comparable. Regardless of personal surgical philosophy, the choice 
of treatment must take into consideration all patient variables, disease etiology, and distinct patient anatomy. What is evident is that we unfortunately still have a long way to go to reduce the mid and long-term morbidity and mortality associated with acute TAAD repair. Until then, the key to improved outcomes remains prompt recognition of malperfusion and restoration of true lumen flow with strict attention to detail at every second of the perioperative period.

\section{References}

1. White A, Bozso SJ, Ouzounian M, Chu WA, Moon MC. Acute type A aortic dissection and the consequences of a patent false lumen. J Thorac Cardiovasc Surg Tech. 2021;9:1-8.
2. Bing F, Rodière M, Martinelli T, Monnin-Bares V, Chavanon O, Bach V, et al. Type A acute aortic dissection: why does the false channel remain patent after surgery? Vasc Endovascular Surg. 2014;48:239-45.

3. Patel HJ, Williams DM, Dasika NL, Suzuki Y, Deeb GM. Operative delay for peripheral malperfusion syndrome in acute type A aortic dissection: a long-term analysis. J Thorac Cardiovasc Surg. 2008;135:1288-95.

4. Geirsson A, Szeto WY, Pochettino A, McGarvey ML, Keane MG, Woo YJ, et al. Significance of malperfusion syndromes prior to contemporary surgical repair for acute type A dissection: outcomes and need for additional revascularizations. Eur J Cardiothorac Surg. 2007;32:255-62.

5. Shrestha M, Martens A, Kruger H, Maeding I, Ius F, Fleissner F, et al. Total aortic arch replacement with the elephant trunk technique: single-centre 30-year results. Eur J Cardiothorac Surg. 2014;45:181-6.

6. Castrovinci S, Murana G, de Maat GE, Smith T, Schepens MA, Heijmen RH, et al. The classic elephant trunk technique for staged thoracic and thoracoabdominal aortic repair: long-term results. J Thorac Cardiovasc Surg. 2015;149:416-22. 